\title{
Effects of RMI 12,936, a synthetic antiprogestational steroid, in the rat
}

\author{
K. E. Kendle \\ School of Pharmacy, Robert Gordon's Institute of Technology, Schoolhill, \\ Aberdeen AB9 IFR, U.K.
}

\begin{abstract}
Summary. The antifertility effect of RMI 12,936 in the rat is shown to be reversible. Luteal hypertrophy followed administration to pregnant, but not to pregnant hysterectomized rats. Similar hypertrophy followed administration to pseudopregnant, immature gonadotrophin-treated, and immature hysterectomized and gonadotrophintreated rats, but the ovarian sensitivity to gonadotrophins was reduced or unchanged, suggesting that the ovarian hypertrophy is due to a direct ovarian action of RMI 12,936. Progesterone production on Day 15 of pregnancy by the enlarged ovaries following RMI 12,936 administration on Day 8 was not significantly different from control levels, but there was a highly significant reduction on Day 9.

An isomer of RMI 12,936, Isomer 201, presumed to be $7 \alpha$-methyltestosterone, was shown to have antifertility and uterotrophic activities in rats similar to those of RMI 12,936. Unlike RMI 12,936, however, Isomer 201 did show significant crossreaction in the competitive protein-binding assay for progesterone and did not cause significant reduction in peripheral progesterone levels on Day 9 after administration on Day 8.

From this and previous evidence it is concluded that RMI 12,936 inhibits progesterone synthesis, possibly by acting as an alternative substrate for ovarian $\Delta^{5}$. ketosteroid isomerase, and that the product is probably a competitive antagonist of progesterone at the receptor level.
\end{abstract}

\section{Introduction}

Previous studies (Kendle, 1975) have shown RMI 12,936 to be of interest due to its high antifertility activity in the pregnant rat coupled with its negligible oestrogenic activity. Termination of pregnancy by administration of RMI 12,936 was associated with significant ovarian hypertrophy but conclusions on the mechanism of action of the compound were tentative. It was believed that the compound could not simply inhibit progesterone synthesis as the antifertility effect could not be reversed by progesterone implants. Failure to displace progesterone from uterine cytosol binding protein made it unlikely, however, that RMI 12,936 was a competitive antagonist of progesterone. Further investigations were therefore undertaken to elucidate the mechanisms involved.

These investigations indicated that RMI 12,936 interrupted ovarian progesterone production. Consideration of the molecular structure of RMI 12,936 and of the process of progesterone biosynthesis led to the possibility that RMI 12,936 was most likely to inhibit progesterone biosynthesis by acting as an alternative substrate for the $\Delta^{5} 3$-ketosteroid isomerase enzyme which normally controls $\Delta^{5}$ to $\Delta^{4}$ isomerization following $3 \beta$-dehydrogenation of pregnenolone (Cheatum \& Warren, 1966). This would lead to a $\Delta^{4}$ isomer of RMI 12,936 which may be a competitive inhibitor of progesterone. This possibility was investigated by subjecting RMI 12,936 to a chemical procedure aimed at producing the $\Delta^{4}$ isomer, $7 \alpha$-methyltestosterone. The product was designated Isomer 201 and some of its biological properties were compared with those of RMI 12,936.

\section{Materials and Methods}

The general methods were as described previously (Kendle, 1975) except that rats of the SpragueDawley strain were used. Comparative experiments showed that these animals were exactly similar 
to the Porton strain used before in their response to RMI 12,936 in antifertility and vaginal cornification assays. Steroids were suspended in an aqueous vehicle containing $0.25 \%$ sodium carboxymethylcellulose $(\mathrm{w} / \mathrm{v})$ and $1 \%$ Tween $80(\mathrm{w} / \mathrm{v})$. Gonadotrophins were dissolved in distilled water immediately before use. Doses were administered subcutaneously in a dose volume of $0.5 \mathrm{ml}$ except where otherwise stated. All surgical procedures were performed under light ether anaesthesia. The methods relating to the separate experiments are given in the 'Results' section. Results, where appropriate and except where otherwise stated, were compared using Student's $t$ test. Logarithmic transformation of the data was used where it was necessary to satisfy the requirements of this test.

\section{Results}

\section{Recovery of fertility after RMI 12,936 administration}

Five mated rats were given 2 mg RMI 12,936/rat on Day 1 of pregnancy while a further 5 were given the vehicle as a control. The animals were caged individually with males of proven fertility, so that fertile mating could occur when normal cycles were resumed after termination of pregnancy by RMI 12,936. Vaginal lavages were taken daily, and when advanced pregnancy was apparent the males were removed and the day of littering and litter size recorded.

The 5 control animals had leucocytic vaginal smears throughout pregnancy and littered on Days 21 (3) or 22 (3) with a mean litter size of 10.4. Administration of RMI 12,936 resulted in cornified vaginal smears on Days 2 and 3 followed by leucocytic smears for approximately 20 days. The animals returned to oestrus on Days 21-23. Normal mating and pregnancy followed the return to oestrus and litters of normal size (mean 11.1) and appearance were produced 40 (1), 42 (2) or 43 (2) days after the first mating.

\section{Luteotrophic effects in pregnant and hysterectomized rats}

Four groups each of 10 mature pregnant females were used. The animals in Groups 1 and 3 were given the aqueous vehicle while those in Groups 2 and 4 each received $2 \mathrm{mg}$ RMI 12,936; the rats in Groups 3 and 4 were hysterectomized. All treatments were on Day 8 of pregnancy and autopsy was on Day 15 when the ovaries were removed and weighed to the nearest $0 \cdot 1 \mathrm{mg}$. Mean ovarian weights were $110 \cdot 4,147 \cdot 4,82.5$ and $95 \cdot 1 \mathrm{mg} /$ pair in Groups 1-4 respectively. Analysis of these results showed that, compared with the control Group 1 , the Group 2 mean was significantly increased $(P<0.01)$ while the means of Groups 3 and 4 were significantly reduced $(P<0.01$ and $P<0.05)$. The means of Groups 3 and 4, however, were not significantly different from each other $(P>0.05)$.

These results confirm the previous indication (Kendle, 1975) that significant ovarian hypertrophy is confined to animals with intact uteri.

\section{Effect on induced corpora lutea}

Corpora lutea were induced in immature rats 3-4 weeks of age by i.p. administration of 10 i.u. FSH (Folligon: Organon) on Day 1 of the experiment followed by 10 i.u. HCG (Pregnyl: Organon) on Day 4. Ten of the animals were then given $2 \mathrm{mg}$ RMI 12,936/rat on Day 5 while the remaining 10 were given the vehicle as a control. Mean ovarian weights, determined at autopsy on Day 12, were 117.4 and $181.7 \mathrm{mg} /$ pair in the control and steroid-treated groups respectively. The difference was highly significant $(P<0.01, t=3 \cdot 818$, d.f. 18$)$.

In a second experiment, mature cyclic rats were made pseudopregnant by mechanical stimulation of the cervix at 12.00 hours on the day of oestrus using an engraving tool (Vibratool: Burgess) fitted with a smooth glass rod. The day of stimulation was designated Day 0 of pseudopregnancy. Decidualization of the uteri was stimulated by mechanical traumatization of the endometrium with a barbed needle at laparotomy on Day 5. One group of animals was then given the vehicle on Day 8 while the other group received $2 \mathrm{mg} \mathrm{RMI} \mathrm{12,936/rat.} \mathrm{The} \mathrm{animals} \mathrm{were} \mathrm{killed} \mathrm{on} \mathrm{Day} 15$ when the ovaries were removed and weighed. Only data from rats in which pseudopregnancy was confirmed by a visible uterine decidual reaction were included in the calculation of mean ovarian weights. 
Mean ovarian weights in the pseudopregnant $(\mathrm{N}=8)$ and pseudopregnant RMI 12,936-treated $(\mathrm{N}=7)$ rats were 71.0 and $116.1 \mathrm{mg} /$ pair respectively. The differences were highly significant $(P<0.01$, logarithmic means 1.84783 and 2.05838 respectively, $t=5 \cdot 85$, d.f. 13 ).

\section{Effect on the response of immature rats to gonadotrophins}

Five groups each of 10 female rats 3-4 weeks of age were given vehicle only (Group 1); 10 i.u. FSH i.p. on Day 1 (Group 2); 10 i.u. FSH i.p. +2 mg RMI 12,936 s.c. on Day 1 (Group 3); 10 i.u. FSH i.p. on Day $1+10$ i.u. HCG i.p. on Day 3 (Group 4); and 10 i.u. FSH i.p. on Day $1+10$ i.u. HCG i.p. on Day $3+2$ mg RMI 12,936 s.c. on Day 3 (Group 5). The animals were killed on Day 4 and the ovaries removed and weighed to the nearest $0 \cdot 1 \mathrm{mg}$. Mean ovarian weights were $18 \cdot 9,58 \cdot 8$, $43 \cdot 5,105 \cdot 8,88 \cdot 6 \mathrm{mg} /$ pair in Groups $1-5$ respectively. The difference between Groups 2 and 3 was significant $(P<0.05)$ while the difference between Groups 4 and 5 was not $(P>0.05)$.

The ovaries were then fixed in buffered $10 \%$ formol saline and sections cut with a freezing microtome. At least 10 sections from different ovaries in each treatment group were photographed and follicle size distribution was estimated by counting the follicles classed as small or large. The results showed that in the FSH-treated animals $41 \%$ of the follicles counted were classed as large, while in the group treated with FSH and RMI 12,936 only $28 \%$ of the total follicles were in this category.

Oviducts from animals given HCG were examined microscopically and large numbers of newly ovulated eggs were observed in all the oviducts of the gonadotrophin-treated animals, including those given RMI 12,936.

\section{Effect on corpora lutea in previously hysterectomized immature rats}

Three groups each of 10 female rats were hysterectomized and then 4 days later given the aqueous vehicle only, FSH + HCG, or FSH + HCG + RMI 12,936 as in the previous experiment. At autopsy 12 days after FSH administration mean ovarian weights were $44.9,87 \cdot 7$ and $125.9 \mathrm{mg} /$ pair respectively. Analysis of these results after logarithmic transformation showed that hysterectomized immature rats responded to gonadotrophin treatment with a significant $(P<0.01$, logarithmic means 1.61971 and 1.92338, $t=4.0298$, d.f. 27) increase in ovarian weight while those animals also given RMI 12,936 showed a further significant increase $(P<0.05$, logarithmic means 1.92338 and 2.06881 , $t=1 \cdot 9305$, d.f. 27).

\section{Effect on systemic progesterone levels}

Blood samples were obtained from anaesthetized rats by cardiac puncture on Day 15 of pregnancy following administration of 2 mg RMI 12,936/rat or the vehicle on Day 8. After bleeding the rats were killed and the number of implantations, number of viable fetuses and ovarian weights were recorded. Serum was prepared and stored at $-20^{\circ} \mathrm{C}$ until assayed for progesterone by a competitive protein-binding method similar to that described by Johansson (1969).

In a further experiment blood was taken on Day 9 of pregnancy after drug or vehicle administration on Day 8.

The results given in Table 1 show that progesterone production from the enlarged ovaries on Day 15 of pregnancy was not significantly different from control output as shown by mean systemic blood progesterone levels. Correlation coefficients between progesterone levels and mean ovarian weights, mean number of implantations, and in the control animals mean number of live fetuses were calculated but none was significant.

Mean systemic progesterone levels on Day 9 of pregnancy following administration of $2 \mathrm{mg}$ RMI 12,936/rat or the aqueous vehicle on Day 8 were 48.0 and $106.6 \mathrm{ng} / \mathrm{ml}$ in test and control groups respectively. The difference was highly significant (Wilcoxon two-sample test, $P=0.004$ ). 
Table 1. Effect of luteal hypertrophy induced by $2 \mathrm{mg} \mathrm{RMI} \mathrm{12,936/rat}$ on Day 8 on systemic progesterone levels at autopsy on Day 15 of pregnancy

\begin{tabular}{lcc}
\hline & Control & RMI 12,936 \\
\hline No. of rats & 5 & 6 \\
Mean ovarian wt (mg/pair) & $123 \cdot 0^{*}$ & $148 \cdot 0^{*}$ \\
Mean no. of implantations & $13 \cdot 8$ & $15 \cdot 6$ \\
Mean no. of viable fetuses & $12 \cdot 4$ & 0 \\
$\begin{array}{l}\text { Mean progesterone concentration } \\
\text { (ng/ml) }\end{array}$ & $167 \cdot 3$ & $144 \cdot 8$ \\
\hline
\end{tabular}

* Significantly different, $P<0.05$.

\section{Chemical isomerization of RMI 12,936}

A sample of RMI 12,936 was heated with $10 \%$ of its weight of anhydrous oxalic acid in ethanol under reflux for $18 \mathrm{~min}$ (Fieser, 1953). The product, recrystallized from ethanol was presumed to be $7 \alpha$-methyltestosterone but was designated Isomer 201 pending confirmation of structure by u.v. spectroscopy and thin-layer chromatography.

\section{Antifertility activity of Isomer 201}

Various dose levels of Isomer 201 were administered to groups of 10 female rats on Day 1 of pregnancy, while further groups of animals were dosed on Day 8. The animals were killed on Day 15 and the contents of their uteri examined. Pregnancy was considered to have been prevented if no live fetuses were found at autopsy.

The results in Table 2 show that Isomer 201 prevented pregnancy in all animals given a dose of $2 \mathrm{mg}$ on Days 1 or 8 but a dose of $0.2 \mathrm{mg}$ was ineffective.

Table 2. Antifertility activity of Isomer 201 in the rat (10/group)

\begin{tabular}{lcccc}
\hline $\begin{array}{c}\text { Dose } \\
(\mathrm{mg} / \mathrm{rat})\end{array}$ & $\begin{array}{c}\text { Day of pregnancy } \\
\text { when dosed }\end{array}$ & $\begin{array}{c}\text { No. of rats } \\
\text { not pregnant }\end{array}$ & $\begin{array}{c}\text { Mean no. of } \\
\text { viable fetuses }\end{array}$ & $\begin{array}{c}\text { Mean no. of } \\
\text { resorptions }\end{array}$ \\
\hline 0.2 & 1 & 0 & $11 \cdot 4$ & 0.8 \\
2 & 1 & 10 & 0 & 0 \\
0.2 & 8 & 0 & 12.6 & 0.6 \\
2 & 8 & 10 & 0 & $11 \cdot 8$ \\
- & - & 0 & 11.8 & 0.4 \\
\hline
\end{tabular}

\section{Preliminary determination of uterotrophic activity of Isomer 201}

Immature female rats 3-4 weeks of age were divided into groups of 5 according to body weight. Various dose levels of Isomer 201 or RMI 12,936 were administered daily for 3 consecutive days. The animals were killed on the day after the last dose and their uteri removed and weighed to the nearest $0 \cdot 1 \mathrm{mg}$. The mean uterine weight for each treatment group was calculated and plotted against the logarithm of the dose. Approximate relative potencies were then determined from the best fitting pair of parallel straight lines.

The results given in Table 3 show that Isomer 201 and RMI 12,936 were approximately equal in uterotrophic activity. 
Table 3. Relative uterotrophic activities of RMI 12,936 and Isomer 201 in immature rats

\begin{tabular}{lccc}
\hline $\begin{array}{c}\text { Compound and } \\
\text { dose } \\
\text { (mg/rat) }\end{array}$ & $\begin{array}{c}\text { Mean uterine } \\
\text { wt (mg) }\end{array}$ & $\begin{array}{c}\text { Equipotent } \\
\text { doses (mg) }\end{array}$ & $\begin{array}{c}\text { Relative } \\
\text { activity }\end{array}$ \\
\hline $\begin{array}{l}\text { Isomer 201 } \\
0.2\end{array}$ & $120 \cdot 3$ & 0.125 & 1.24 \\
0.064 & 93.3 & & \\
0.02 & 53.4 & & \\
$R M I 12,936$ & & & \\
0.2 & 113.0 & 0.155 & 1.00 \\
0.064 & 76.5 & & \\
0.02 & 67.5 & & - \\
Controls & 49.6 & - & - \\
\hline
\end{tabular}

\section{Conversion of RMI 12,936 to Isomer 201 by homogenates of pregnant rat ovaries}

The ovaries from 3 rats killed on Day 16 of pregnancy were homogenized in $10 \mathrm{ml}$ Krebs-Ringer phosphate buffer, $\mathrm{pH} 7 \cdot 4$, using a glass homogenizer with a mechanically driven Teflon pestle (Thomas tissue grinder) for $2 \mathrm{~min}$ at $0^{\circ} \mathrm{C}$. The homogenate was centrifuged at $800 \mathrm{~g}$ for $10 \mathrm{~min}$ to remove cellular debris and $4 \mathrm{ml}$ aliquots of the supernatant were taken for incubation. A solution of $1.2 \mathrm{mg} \mathrm{RMI} 12,936 / \mathrm{ml}$ ethanol was prepared immediately before use, $100 \mu$ lof this solution being added to $4 \mathrm{ml}$ buffer or ovarian homogenate to give a final concentration of steroid of $10^{-4} \mathrm{M}$.

Three tubes were prepared for incubation. These contained $1 \times 10^{-4} \mathrm{M}-\mathrm{RMI} 12,935$ in buffer, ovarian homogenate; and $1 \times 10^{-4} \mathrm{M}-\mathrm{RMI} 12,936$ in ovarian homogenate. Incubation was at $37^{\circ} \mathrm{C}$ for $45 \mathrm{~min}$ before $4 \mathrm{ml}$ hexane were added to each tube and the tubes shaken by hand for $1 \mathrm{~min}$. The hexane layer was then removed and the u.v absorption spectrum examined using the SP800 recording spectrophotometer.

Incubation of RMI 12,936 with ovarian homogenate resulted in the formation of a peak in the u.v. absorption spectrum at $243 \mathrm{~nm}$ while incubation with buffer did not. Extraction of ovarian homogenate without added steroid also yielded no peak in this region of the u.v. absorption spectrum.

\section{Cross-reactions of RMI 12,936 and Isomer 201 in the progesterone competitive protein-binding assay}

Cross-reactions of RMI 12,936 and Isomer 201 were studied using the method described by Johansson (1969). Graded amounts of each steroid were added to assay tubes and the amount producing $50 \%$ depression of activity determined. This value was related to the amount of progesterone producing $50 \%$ depression and the percentage cross-reaction determined.

The results showed that the cross-reactions of RMI 12,936 and Isomer 201 were 0.51 and $7.8 \%$ of the activity of progesterone respectively. The extraction from plasma by petroleum ether of RMI 12,936 was $100 \%$ so its effective cross-reaction in the assay was also $0.51 \%$. The petroleum ether extraction of Isomer 201, however, was $63.7 \%$ and its effective cross-reaction in the assay was $4.96 \%$ These results show that Isomer 201 has a much greater affinity than RMI 12,936 for the proteinbinding sites in this system.

\section{Effect of Isomer 201 on progesterone production}

Four groups of animals were used in the experiment: (i) ovariectomized on Day 8 of pregnancy; (ii) ovariectomized and given a s.c. injection of $2 \mathrm{mg}$ Isomer 201/rat on Day 8; (iii) intact and treated with $2 \mathrm{mg}$ Isomer 201/rat; and (iv) intact, untreated controls. Blood samples were obtained by cardiac puncture on Day 9, serum prepared and assayed for progesterone as before.

The results showed that the mean systemic progesterone level in pregnant rats was $10.3 \mathrm{ng} / \mathrm{ml}$ $24 \mathrm{hr}$ after ovariectomy compared to $65.0 \mathrm{ng} / \mathrm{ml}$ in intact controls. Administration of $2 \mathrm{mg}$ Isomer 
201/rat increased the apparent progesterone concentration in pregnant ovariectomized rats to $23.1 \mathrm{ng} / \mathrm{ml}$ due to its effective cross-reaction in the assay. In intact pregnant rats treated with Isomer 201 the assayed level of progesterone was $67.3 \mathrm{ng} / \mathrm{ml}$. After making allowance for the cross-reaction of Isomer 201 in the assay there was no evidence of a significant reduction in progesterone production in pregnant rats given Isomer 201 compared with that in pregnant controls.

\section{Discussion}

Previous studies (Kendle, 1975) have shown that administration of RMI 12,936 terminated pregnancy following administration on Day 1 in the rat by causing acceleration of tubal transport followed by expulsion of fertilized eggs via the vagina. The results of the present study indicate that fertility is regained at the end of a period equivalent to the duration of normal pregnancy in animals given this treatment. This indicates that the effects of RMI 12,936 are readily reversible but further indicates that the drug has no effect on the lifespan of the corpora lutea of pregnancy as the treated animals returned to oestrus at approximately the same time as the pregnant controls produced their litters. This finding is of particular interest as it may reasonably have been expected that following termination of pregnancy before implantation the lifespan of corpora lutea would have been confined to the 10-14 days characteristic of pseudopregnancy, as is the case following treatment with oestrogens (K. E. Kendle, unpublished observations).

Administration of RMI 12,936 on Day 8 of pregnancy has been shown to produce significant ovarian hypertrophy in intact pregnant rats but not in pregnant hysterectomized or mature cyclic animals. Further investigation of this finding was necessary, however, as the experimental designs used allowed only within-experiment and not between-experiment comparisons (Kendle, 1975). The present results extend the original observation to show that hysterectomy prevents the luteal development associated with normal pregnancy and also prevents the hypertrophy caused by RMI 12,936. These findings are therefore compatible with the hypothesis that RMI 12,936 induces ovarian hypertrophy in the pregnant animal through a luteotrophic factor of uterine origin, the production of which is confined to the pregnant uterus.

The investigations on induced corpora lutea in immature rats and mature pseudopregnant rats, however, indicated that significant ovarian hypertrophy followed administration of RMI 12,936 to these animals which had functional corpora lutea. It was considered to be unlikely that the capacity to produce a luteotrophic factor was shared by the mature pregnant uterus, the pseudopregnant uterus and the immature gonadotrophin-stimulated uterus but was absent from the uterus of the mature cyclic animal (Kendle, 1975). Other explanations for these observations were therefore investigated. The results indicated that administration of RMI 12,936 reduced the ovarian sensitivity to exogenous FSH and did not alter sensitivity to exogenous LH in immature rats. It may be concluded, therefore, that the mechanism of ovarian hypertrophy in the immature gonadotrophintreated animal is not due to increased sensitivity to pituitary gonadotrophins and that RMI 12,936 produces its effects on functional corpora lutea by direct action at the ovarian level. It would therefore be anticipated that the compound should produce hypertrophy in the ovary of the hysterectomized pregnant rat unless this was prevented by some other factor such as interruption of ovarian blood supply by the ligatures on the uterine blood vessels used to control haemorrhage at hysterectomy. This possibility was examined by investigation of the effects of RMI 12,936 on corpora lutea induced in immature animals previously hysterectomized. Hysterectomy could be carried out in these animals without ligation of blood vessels and the response to gonadotrophins provided an indication of ovarian sensitivity to known trophic stimuli. The results show that, under these conditions, the animals were able to respond both to gonadotrophin stimulation and to administration of RMI 12,936 , confirming that the effects of the latter are probably direct effects at the ovarian level.

The results of the experiments to determine whether the compound altered the capacity of the pregnant ovary to produce progesterone show that systemic progesterone levels on Day 15 of pregnancy following administration of RMI 12,936 on Day 8 are not significantly different from control levels, despite significant ovarian hypertrophy. If, therefore, a greater mass of luteal tissue is 
producing a normal level of progesterone, it may be concluded that the efficiency of the synthesis is reduced. This was investigated by measuring progesterone levels $24 \mathrm{hr}$ after RMI 12,936 administration, when a highly significant reduction was observed, confirming that the compound is an inhibitor of progesterone synthesis. Previous studies (Kendle, 1975), however, have shown that pregnancy could not be maintained by progesterone implants in RMI 12,936-treated animals, although pregnancy was maintained in ovariectomized animals, indicating that RMI 12,936 inhibited progesterone activity rather than synthesis. Evidence against this hypothesis on the basis of the failure of RMI 12,936 to displace progesterone from human uterine cytosol protein was also quoted. In view of these findings and the present results, investigations were undertaken to attempt to resolve these apparent contradictions.

RMI 12,936 was subjected to a chemical procedure aimed at producing the $\Delta^{4}$ isomer, $7 \alpha$-methyltestosterone. The antifertility and uterotrophic activities of this compound, designated Isomer 201, were found to be similar to those of RMI 12,936. Furthermore, incubation of RMI 12,936 with homogenates of pregnant rat ovaries is shown to yield a product whose u.v. absorption spectrum is identical with that of the chemically prepared Isomer 201. It is concluded from these results that RMI 12,936 may inhibit progesterone biosynthesis by acting as an alternative substrate for ovarian $\Delta^{5} 3$-ketosteroid isomerase and that the isomerization product also has antifertility activity. The cross-reaction of RMI 12,936 in the competitive protein-binding assay for progesterone was negligible; the cross-reaction of Isomer 201 was much greater, although still much less than progesterone. If these differences in binding provide an indication of different affinities of the molecules for progesterone receptor sites, they support the concept that while RMI 12,936 is not a competitive antagonist of progesterone, Isomer 201 is likely to be a competitive antagonist at the receptor level. This possibility requires further investigation, however, as Isomer 201 is almost certainly $7 \alpha$-methyltestosterone. While Isomer 201 is shown to significantly cross-react in the assay used based on progesterone binding to a human serum protein, $7 \alpha$-methyltestosterone has been reported to have less than $0.5 \%$ cross-reaction in a similar assay using guinea-pig serum binding protein (Tan \& Murphy, 1974). Further work will therefore be undertaken to confirm that Isomer 201 is $7 \alpha$-methyltestosterone and to investigate cross-reactions in other progesterone binding systems. The present results indicate that Isomer 201, unlike RMI 12,936, does not cause significant inhibition of progesterone biosynthesis. It may therefore be concluded that the action of Isomer 201 is probably on progesterone utilization and provides further support for the hypothesis that this metabolite is a competitive antagonist of progesterone.

The present study provides further support for the original hypothesis (Kendle, 1975) that the antifertility effect of RMI 12,936 is due to antiprogestational activity and that the compound appears suitable for development as a contraceptive for dosage at monthly intervals. Further investigation of the compound will therefore be undertaken. In particular, attempts will be made to elucidate the biochemical and histological effects on the ovary, the fate of the corpora lutea after Day 15 of pregnancy following administration on Day 8 and the nature of the uterine response to the compound.

I thank Dr V. Petrow and Merrell National Laboratories, Division of Richardson Merrell Inc., Cincinnati, Ohio, for supplying the compound RMI 12,936; Professor A. Klopper and Mr D. Bruce, Department of Obstetrics and Gynaecology, Aberdeen Royal Infirmary, for providing laboratory facilities for and carrying out the progesterone assays; Dr D. Hardy, School of Pharmacy, Robert Gordon's Institute of Technology, Aberdeen, for producing Isomer 201 and investigating its structure; Dr K. T. Kirton, the Upjohn Company, Kalamazoo, Michigan, for supplying a sample of $7 \alpha$-methyltestosterone; and Mr A. Wilson, School of Mathematics, Robert Gordon's Institute of Technology, Aberdeen, for the statistical analysis of results.

\section{References}

Cheatum, S.G. \& Warren, J.C. (1966) Purification and properties of $3 \beta$-hydroxysteroid dehydrogenase and $\triangle^{5}$ 3-ketosteroid isomerase from bovine corpora lutea. Biochim. biophys. Acta 122, 1-13. 
FIESER, L.F. (1953) Cholesterol and companions. VIII. Steroid dibromides J. Am. chem. Soc. 75, 5421-5422. Johansson, E.D.B. (1969) Progesterone levels in the peripheral plasma during the luteal phase of the normal human menstrual cycle measured by a rapid competitive protein binding technique. Acta endocr., Copenh. 61, 592-606.
KENDLE, K.E. (1975) Some biological properties of RMI 12,936, a new synthetic antiprogestational steroid. J. Reprod. Fert. 43, 505-513.

TAN, S.Y. \& MURPHY, B.E.P. (1974) Specificity of the progesterone binding globulin of the guinea pig. Endocrinology 94, 122-127.

Received 30 April 1976 